\title{
O melhor do discurso patriarcal em linhas e formas
}

\author{
Juliano Benatti Machado Paz ${ }^{1}$
}

Ana Maria Colling, é Doutora em história pela UFGD, e seus trabalhos sobre gênero são famosos pelo tom feminista. Já escreveu outros livros, mas este dividido em capítulo I, as questões para pensar o feminino e no capítulo II, tempos diferentes, discursos iguais, em especial, tem uma forma que nos leva a analisar o discurso patriarcal que construiu "verdades" com o passar dos séculos e não condizem com os anseios, desejos e sonhos das mulheres de hoje, do século XXI.

A imposição velada em cada momento de relação social da mulher com o próximo, a reprodução de comportamentos machistas de mulheres para com as mulheres. O sentimento de que sempre esta faltando algo que, mesmo tudo que já foi conquistado surge um quebra cabeça na vida. Como juntar essas peças? Colling faz isso com grande maestria, descreve sobre a dominação masculina. Pronuncia esclarecendo que a história era uma profissão de homens escrevendo sobre homens e se fazendo uma história universal, deixando de lado ou a margem o "grande espírito feminino".

Sem duvida, até pouco tempo não tinha como ir contra essa corrente de conceitos masculinos. Embora Colling nos mostra que sim, tem uma história das mulheres que os discursos, por mais precisos que são, relatam apenas os feitos masculinos, a história do discurso é hierarquizado e desvaloriza o feminino perante o masculino.

\footnotetext{
Na história das mulheres a dimensão da linguagem, dos discursos, passa as ser uma ferramenta de análise importante, agora não mais como meio de representação da realidade. A linguagem não é só vocabulário, mas discurso que numa relação de saber e poder, determina verdades e nos subjetiva (COLLING, 2014, p36)
}

Essas artimanhas são na verdade, características socialmente construídas.

${ }^{1}$ Graduando em História pela Faculdade de História da UFG e bolsista PIVIC.

julianobenatti29@gmail.com 
A autora ressalta que a história tem que ser reanalisada, os discursos históricos construídos por autores masculinos devem ser revistos, pois, há mais que um campo de dominação. Há uma luta de resistência às normas e regras, as possibilidades e sujeitos transgressores ficaram calados ou calaram seus atos contra a manipulação do "grande espírito feminino".

A inclusão e reconhecimento que as mulheres tiveram na história não significa apenas uma parte da população, significa mudar a história como nos foi apresentada. Esta visibilidade trás consigo também a sexualidade dos homens, uma nova perspectiva de ralação de poder. Não tem o sexo mais forte, tem o sexo, cada um com suas limitações e suas distintas habilidades.

O livro implica em uma história das mulheres, novas categorias de analises do pensamento e conceitos aplicados. Rever a história desde o início, começando pelos textos médicos e filosóficos que são incorporados nos discursos pedagógicos, em detrimento da imagem feminina e suas praticas cotidianas. A natureza feminina de seu corpo serve como apoio aos discursos de fragilidade e com um aspecto negativo, isto na visão machista da historia da humanidade.

Mais um ponto que nos é apresentado refere-se a descentralização do sujeito, não para negar, mas para situar o sujeito, vendo suas características e reconhecer as diferenças, podendo identificar como foi feito esse discurso de construção e hierarquização dos sexos. O modo mais eficiente de desmontar esses discursos que parecem imutáveis é mostrar como isso foi produzido, como algo que parece concreto não passa de uma construção frágil, sem adotar as possibilidades de outras personagens, determinando fatos como universais.

A história das mulheres vai além do lar, e isso é um perigo para esses discursos universais, mostra que são potentes, mas não trarão o caos a ordem pública, e sim a ordem natural. As mulheres que transgrediam essas leis morais como diz a autora, tornavam-se homens, sair dos costumes transformava a mulher em aberração, uma maneira de impedir que a mulher lhe tomasse a identidade, ou o solo seguro.

A Revolução Francesa mostra bem o exemplo das barreiras que as mulheres sofreram para derrubar. Uma delas é Olympe de Gouges, foi decapitada em 1793 como não seguiu a ordem natural do casamento, da maternidade o que era a vida de toda mulher, conseguiu se alfabetizar sozinha aos 32 anos e foi incriminada por tentar ser um homem ao trair o curso da natureza de seu sexo e não se dedicar apenas as paredes de seu lar.

A influência das narrativas para escrever e trabalhar com o imaginário e o ideal do pensamento masculino, as práticas que definem o espaço limitado da mulher, isso tudo não passa de uma obra de construção simbólica, nunca é neutra. O que está determinado ou delimitado pelo sexo é apenas uma criação do homem, como se fosse uma cultura natural, se retirarmos a vaidade masculina a natureza do sexo não tem diferença. A categoria de gênero passou a ser utilizada na luta pelo espaço que é de direito da mulher, passou a ser uma ferramenta contra a discriminação. 
Essa separação dos sexos, na história, na construção identitária, sempre foi de modo pejorativo, eleva se o homem como universal é um disfarce do falocentrismo. O sexo feminino é sempre visto como o negativo, o passivo o pecador.

Os discursos, muitos duradouros, a questão da procriação contribuiu muito para perjúrio da imagem feminina. Tais práticas, radicais ou subliminares foram feitas e podem ser desfeitas, desde que saiba como foram feitas e aceitas.

O maniqueísmo está presente e é parte fundamental para os discursos, mostram a dualidade que servia como base para a filosofia da desqualificação e submissão da mulher. Esse por sua vez trata a mulher como incapazes de liderar, ou dominar, descontroladas e emocionalmente pouco aptas a suas paixões. O inverso desse discurso, de modo mais brando mas com grande significância, é o de frágeis, guiadas pelas emoções, contrarias as guerras, pudicas.

\footnotetext{
Os discursos são construídos levando em conta um sistema de categoria binária, de pares dualistas, que opõe Sol e Lua, alto e baixo, direita e esquerda, claro e escuro, brilhante e opaco, quente e frio, seco e úmido, superior e inferior, público e privado, feminino e masculino, natureza e cultura (COLLING, 2014, p.43-44)
}

Certos discursos que ou as tornam verdadeiras santas, ou a encarnação do demônio. Trabalham bem o psicológico, biológico e o morfológico. Este caráter de imperfeição às levam a submissão aos falos e viris cavalheiros. Mal sabiam que se as mulheres se sujeitavam a tal submissão era por uma questão de sobrevivência e não de acomodação. Como sobreviver nessa cultura? Deixando seus sonhos e vontades para segundo plano. Ser modelo de boa esposa, filha, moça direita, o maior desejo era de sobreviver.

Interessante o livro traz várias análises e esmiúça cada um dos discursos feitos no decorrer da história dos homens. O pensamento de Platão sobre a educação das mulheres era de certo modo era desqualificando para qualificar, Platão diz que a educação deve ser igual para homens e mulheres, a diferença do sexo não produz diferença nas atitudes.

O discurso religioso também é forte quando se trata de desqualificar a mulher. O pecado original é graças a Eva, tratada como um ser desprovido de intelecto, ouse não fosse de intelecto baixo e fraco resistiria às tentações de Satanás. A autora em outras publicações já havia nomeado "os três bastiões de resistência às mulheres", fazendo uma comparação com a IdadeMédia, o militar, o político e o religioso, acredita que o político e o militar possivelmente abram espaço para a mulher, e o religioso demore um pouco mais.

Nossa autora faz uma analise de onde nasceram os pré-conceitos, hoje estão muito a frente, dos locais onde adotaram, onde não foi criado, e seguiram essa linha de submissão feminina. Perpetua até os tempos de hoje.

O discurso médico também ajudou muito para tornar a mulher inferior. O corpo feminino era visto como lugar de procriação das enfermidades dos homens, as doenças que 
atingiram e dizimaram cidades, eram causadas pelas mulheres. Seus corpos pecaminosos também traziam as pragas.

O discurso o psiquiátrico que se desenvolve junto com o discurso médico. Surge a difamação que o período menstrual deixava a mulher uma inválida. Afetava não só o físico mas o controle psicológico. A mulher que estava menstruada estava passando por um período de loucura e violência. Seu comportamento era visto como demência.

O discurso psicanalítico surge da doença das mulheres, a histeria, apresentado por Sigmund Freud, este apresenta duas teorias, a da sexualidade lembrando muito a medicina filosófica, e a outra revoluciona profundamente. A teoria de que o homem tem conhecimento de si. Infelizmente tem uma característica limitada dos papeis sociais, mas ao evidenciar a importância da sexualidade na construção da personalidade feminina, fica conhecido pela sua originalidade.

Ao afirmar que do pensamento e ações de escritores importantes da história, a subordinação imposta às mulheres, muda de corpo, forma e narrativa, mas não muda o ideal masculino de exploração. As relações de poder tornam-se menos evidentes.

\begin{abstract}
A concepção de feminino e masculino, o que é ser mulher e ser homem na sociedade, é decorrente de vários discursos normatizadores que delimitam as práticas sociais. As determinações pretensamente científicas, que insistiam na inferioridade e subordinação das mulheres, se converteram em tradições e atravessaram os tempos. O discurso da diferença biológica, e como decorrência, a hierarquia entre os sexos inaugurada pelos gregos assumem um caráter universal e exercem influencia decisiva, tanto na vida cotidiana como na elaboração das constituições e códigos ocidentais (COLLING, 2014, p. 101-102)
\end{abstract}

A produção e configuração das leis de igualdade não são justas, nem no privado quanto no coletivo. Argumenta sobre o modo como deveria ser. Criar uma nova metáfora para entender as novas leituras de relações sociais.

Como discursos normativos nos faz acreditar que entendemos as diferenças que não são claras. Os diferentes modos de discursos baseados em critérios científicos para inferiorizar as mulheres. Outros se tornaram discursos universais.

A partir de quando surgiram debates sobre o assunto de gênero, a história teve que ser revista. Obrigou homens a considerar que mulheres não vieram ao mundo apenas para procriar, ou para serem meras donas do lar. Menos ainda, serem reconhecidas como "uma boa mulher" por ser obediente aos mandos e desmandos dos caprichos machistas.

As mulheres não lutam pelos direitos que agora vigoram. Lutam por direitos descentes, sem exploração de qualquer que seja o gênero. Pode se dizer que o livro da autora Ana Maria Colling tem um sonho nas entre linhas. Deseja que as relações sociais mudem, melhorem e não desqualifiquem o feminino por suas diferenças. 